\title{
Erratum to: Analytic Function Theory of Several Variables
}

\section{Erratum to:}

J. Noguchi, Analytic Function Theory of Several Variables, DOI 10.1007/978-981-10-0291-5

The book was inadvertently published without including the following mandatory information shown in the contract, "Copyright for the Japanese edition (C) 2013, Asakura Publishing Company, Ltd. All Rights reserved". The erratum book has been updated with the change.

The updated original online version for this book can be found at DOI 10.1007/978-981-10-0291-5.

J. Noguchi $(\bowtie)$

The University of Tokyo, Tokyo, Japan

e-mail: noguchi@ms.u-tokyo.ac.jp

J. Noguchi

Tokyo Institute of Technology, Tokyo, Japan

(C) Springer Science+Business Media Singapore 2016 